\title{
Multimedia Design and Application in Teaching Chinese Language and Literature
}

\author{
Shuwen Wang ${ }^{1, a}$ \\ ${ }^{1}$ Teacher's College, Beihua University, Jilin 132013, China. \\ ashuwen_wang@126.com
}

Keywords: Chinese language and literature, teaching, MCAI.

\begin{abstract}
With rapid development of teaching Chinese language and literature, more and more foreign students are focusing on how to improve the literary training levels. Meanwhile, rapid growth of the wide application of the computer, has made Multimedia Computer-Assisted Instruction (MCAI) a hotspot in applications of teaching Chinese language and literature. In this paper, multimedia teaching modes designing has been developed for teaching Chinese language and literature scenes, which would be greatly improved. and applying MCAI courseware have bring MCAI into teaching practice, so that teaching quality is greatly improved.
\end{abstract}

\section{Introduction}

With China's economic development and national strength, the number of people learning Chinese in the world is growing at an unprecedented rate. As of December 2010, the total number of people learning Chinese in the world has reached 40 million, not including native Chinese countries and regions, and the number of people learning Chinese is growing at an annual rate of increase of 500\%. According to statistics, there are now more than 100 countries of the world nearly 4,000 colleges and universities offering Chinese courses. In order to meet these shares learning Chinese craze for Chinese language teachers around the world to meet the needs of many domestic universities have set up a Foreign Language Professional: from Beijing Language and Culture University, East China Normal University, Beijing Foreign Studies University and Shanghai International Studies University in 1985 first established outside since the Chinese Major, after nearly 26 years of development, in the common interest of the state and society, the rapid development of Foreign Chinese Major. By the end of 2010, the country has 285 colleges and universities offer the profession each year enrollment reached more than 15,000 people, for the society at all levels of foreign language teacher talent. At the same time, in order to promote international cooperation and exchange of Chinese as a second language teaching and research, and promote the development of Chinese Language Teaching and research related to learn have been established, and periodic seminars, in-depth on the hot issues of the development of Chinese language teaching discussion and exchange.

Concerned about Chinese teaching and research process, how to adopt better teaching methods to improve the quality of teaching has become the subject of attention. While Chinese teaching development, the rapid development of technology to provide people with new ideas, especially the development of computer information technology and its application in the field of education matures, causing a computer to use in the outward Chinese arouse sufficient attention. In the beginning of this century, namely Zhao Jinming pointed out, it should be multi-perspective thinking to study Chinese Foreign disciplines, and should be noted as a Foreign Language "linguistics, psychology, education, linguistics and computer Modern Educational Technology crossroads . " In fact, the "computational linguistics and modern educational technology" that is the subject Foreign Language on the Tools on the level of attention should be raised and discussed areas.

In view of this, the Chinese Foreign Experience and research-oriented teaching computer-aided design and application, for the development of computer-assisted language teaching, and effectively improve the teaching quality and effectiveness, has very important significance. Meanwhile, computer-assisted language teaching applications will also become a major concern of foreign 
instruments and teaching Chinese, related study foreign language teachers should be more concerned about the topic.

\section{Prospects Computer Aided Chinese Teaching}

Issues related to computer-assisted language teaching more and more people's attention, exchange activities at home and abroad has become more frequent. Up to now, the international Chinese teaching seminar has been held the tenth, each session has an associated topic and discussion; the World Chinese Language Teaching organized by the Taiwan World Chinese Language Education Society organized specially set up to discuss the work of computer-assisted language teaching Square; in addition, the global network of Chinese educational seminars international Conference on computer Teaching Chinese as well as the international Conference on Chinese electronic teaching mentioned before are specialized seminar computer Assisted instruction. Holding of its development and the meeting point of view, research in this area is very active, update speed is very fast.

In terms of implementation, computer-aided design to improve the study of teaching Chinese language teaching, strengthen the construction of teaching system technology, explore new models of computer-aided teaching and so become a topic of concern and further explore objects. Foreign computer-assisted teaching Chinese is a typical cross-discipline, its development is inseparable from the computer platform and its support in the external environment, but also inseparable from the results of research and study of Chinese language teaching body. Therefore, the development of computer technology is important, teaching workers to foreign language teaching experience summary and analysis of advancing their development, enhance their teaching effectiveness is essential.

\section{Teaching Chinese as a multimedia courseware design and production}

Any one need to go through a good software from planning to design, modify, and through continuous improvement process, the courseware is no exception. A textbook, a class supporting courseware production often takes a lot of thought, a lot of energy in the process of classroom use also need to feedback and continue to improve. Overall, courseware design should include the following major steps:

It must first analyze its necessity and possibility before making multimedia courseware, courseware use to analyze and determine what can be achieved, in line with objectives proposed teaching needs. Courseware design for language teaching should pay special attention to how to play to the characteristics of multimedia technology. The purpose of this stage must be clear in the use of courseware, courseware aimed at using objects (students), learn to understand their characteristics and possess Chinese level. This requires a foreign language teacher for foreign students Chinese acquisition characteristics, background levels of Chinese have more understanding.

Subject teaching is teaching object. In the learning process, each student is a separate entity with its own learning characteristics, therefore, the individual characteristics of the students during the teaching must attach importance to the design of. Students features include: knowledge of the original structure, the original cognitive ability, what they learn attitudes, learning styles and even personality traits, and so on. In practice, foreign language teaching, teachers can be organized by language test, observe the performance of students in the class, the lower class or learn other methods to determine the exposure of the original knowledge structure and cognitive characteristics of students, and one recorded as the primary basis for determining teaching objectives and teaching methods, in order to create more targeted multimedia courseware.

As we all know, Chinese textbooks written language is not simply a pile of material, an interlocking system of teaching but through rigorous design of the system is formed, and therefore, every chapter, every one lesson, each lesson has even its preset goals. Because multimedia courseware only as a means of teaching, therefore, the same as with traditional classroom instruction, before determining the specific teaching methods, the development of effective teaching strategies 
must be based on a complete analysis through the clear teaching objectives based on the teaching content. This requires teachers should fully respect the textbook set teaching objectives, based on the content of textbooks, to find the relationship between the structure of knowledge, according to the teaching objectives and teaching content accordingly, choose a suitable teaching model, in order to better reach a preset teaching effect. After teaching goal is for students by teaching activities to achieve what kind of level, can be learned to do kind of what estimates were clear and specific formulation. Analysis of classroom teaching objectives in favor of standardization and Benefits "education" focused, prioritize, but also helps to reduce the "learning" blindness to enhance student initiative. At the same time, teaching objectives specific and explicit also helps develop a reasonable and practical teaching strategies.

Analysis of teaching content and teaching objectives analyze the relationship between the two are complementary: the teaching content is based on teaching goals as a starting point, but they can not be divorced teaching objectives teaching content and independent existence. Therefore, the analysis must be based on teaching content teaching objectives as the basis for the purpose of teaching as a guide to delimit the scope of teaching content, depth and composition of the teaching content and reveals contact portion, so as to achieve optimal teaching effect. Thus, the preparation of a multimedia courseware should first consider what the purpose of teaching is, overall what requires students to master the language or cultural knowledge which, after the classroom teaching students to take advantage of the knowledge of what to complete communicative tasks and many more.

Teaching strategy is to consider the overall procedures, methods, forms and other media elements to accomplish specific objectives of teaching and the use of teaching and learning activities. Teaching strategies are not mandatory and rigid, it has great flexibility. Courseware itself not to exist, its ultimate aim is to achieve more assist teaching functions, a good multimedia courseware should have four functions: help to stimulate students' interest in learning and learning initiative; conducive to knowledge obtaining and maintaining; can realize effective teaching information organization and management; you can create the best learning environment for students.

How best to achieve the effect of courseware used? The most important thing is to fully stimulate interest in learning. Traditional "spoon-feeding" teaching just copy and paste existing knowledge, but can not inspire and develop students' creative thinking. Only when students have a strong interest in the course, will have a more active learning, mastery of knowledge it will become easier. Courseware, many times you need to insert vivid graphics, animation and even video, so that one can say the problem more clearly, it can also attract the attention of students. We should make full use of advanced resources, we strive for the best teaching effect. Excellent foreign language teachers should have a sense of acceptance and application of information technology, scientific ideas and concepts of education, but also has a strong desire to learn continually receiving new knowledge and advancing learning ability can always keep pace with the times, not out of line with the new era, new technologies, new educational philosophy.

\section{The basic principles of courseware design}

To design a real and effective courseware, we must first grasp the basic principles of courseware design, with the scientific design standards in order to guide us in the right direction to keep courseware production. Otherwise, simply move the materials, or the blind pursuit of fancy layout, display technology, will deviate from the original intention, failing to meet the teaching objectives. Specifically, the basic principles of courseware design generally have the following points:

Student-centered, teacher-led, fully mobilize the enthusiasm of students and initiative is a fundamental principle of foreign language teaching classroom. Multimedia computer assisted instruction courseware as a means, it has played a role in traditional teaching writing on the blackboard, even to some extent replaced the role of teachers. Thus, the "words and deeds", "every move" will play an exemplary role, from the writing to the content of expression should be scientific, standards and norms, to provide students with an accurate mold of the present. For example, the Chinese character strokes, stroke order to be compliant, pronunciation must be accurate; pinyin and 
text content to be accurate; science to explain the words, examples must be standardized and practical; to explain the intricacies of sentences or language points to choose their students' language level words or graphics, video, etc., or be explained by the students' native language. As another example, the choice of font should fully consider the characteristics of students, students to choose easily recognizable font, do not use WordArt or ligatures, or give students the basic obstacle identified, thus affecting the effectiveness of teaching.

\section{Summary}

Teachers' own level to really play the role of multimedia courseware, educational technology and services to achieve a modern classroom teaching objectives, to enhance the quality of foreign language teaching classroom plays the most crucial impact. Based on this, in order to assist the multimedia classroom teaching methods to better play its role, we need to develop both a solid grounding in a number of Chinese body of knowledge, but also on teaching methods and techniques has accurately understand and grasp, but to master multimedia computer Foreign Language teachers representative of modern educational technology. Excellent foreign language teachers should have a sense of acceptance and application of information technology, scientific ideas and concepts of education, but also has a strong desire to learn continually receiving new knowledge and advancing learning ability can always keep pace with the times, not out of line with the new era, new technologies, new educational philosophy. From the school's point of view, it should be an organized, planned way foreign language teacher training, through training, teachers update their knowledge and mastery of technology, reconstruction concept, fully aware of the role of modern information technology in education and teaching, and new teachers are required to continue to put right. Extensive use of multimedia technology in education is a big trend in the development of education and teaching, and therefore will become every teacher needs to learn and master the necessary skills. A good foreign language teachers, not only have excellent knowledge of the Chinese body, adequate education, psychology accomplishment, rich classroom experience, but also able to skillfully operate a computer, make full use of network resources, the rational design of multimedia courseware, and rational use of energy in the classroom, improve teaching quality and effectiveness.

\section{References}

[1] Ouyang Lin Qiao. Three Theoretical analysis of the influence Multimedia Assisted Language Teaching. Economic and social development, 2013.7.

[2] Song Jihua Wu Xu Juan Hill. Teaching Chinese as a network courseware making three errors. China Educational Technology, 2014.5.

[3] Song Jihua Xu Xu Juan see hung. Teaching Chinese as a network courseware development of theoretical principles. Beijing Normal University, 2014.2.

[4] Wu Qianlong Second Language Acquisition Process of Cognitive Psychology. Foreign Language Teaching and Research, 2010.4.

[5] Yang Tianming Weizeng Ju Cao Wenfeng and universities Multimedia Classroom discussion plains University, 2014.6.

[6] Yanghui Fen, Zhang Chunping multimedia teaching Chinese Foreign 21st Century Teaching Chinese Foreign important means for Chinese Language Teaching, 2009.2.

[7] Wang Jinlong design and application of multimedia courseware in teaching Chinese Language Foreign Taiyuan University of Technology, 2012.9. 